\title{
How to Gamify Online Business: A Case Study Based on "SMART" Model
}

\author{
Hui Xu \\ Shanghai Maritime University, Shanghai, China \\ Email: xuhui190@126.com
}

How to cite this paper: $\mathrm{Xu}, \mathrm{H}$. (2020). How to Gamify Online Business: A Case Study Based on "SMART" Model. Journal of Service Science and Management, 13, 516-534.

https://doi.org/10.4236/jssm.2020.133034

Received: May 2, 2020

Accepted: June 7, 2020

Published: June 10, 2020

Copyright $\odot 2020$ by author(s) and Scientific Research Publishing Inc. This work is licensed under the Creative Commons Attribution International License (CC BY 4.0).

http://creativecommons.org/licenses/by/4.0/

(c) (i) Open Access

\begin{abstract}
With the explosive development of online information, attracting people to participate in online business activities has become a practical challenge which is needed to be solved. Gamification is one of the effective ways to solve this problem. However, there is still a lack of systematic understanding and effective use of gamification due to the diversity of gamification features. More importantly, most classification methods for gamification features cannot provide guidance for practices of online business. Designers and managers of online business are facing the challenge of applying gamification features to engage their users. Therefore, in this study, a new model (SMART) has been put forward to categorize gamification features by reviewing the prior literature. Each feature of the SMART Model has been further analyzed based on a case study of a successful gamified online trading platform (Xian-Yu) in China. This study provides a practical reference for the adoption of gamification in online commerce.
\end{abstract}

\section{Keywords}

Gamification, Motivational Affordance, Gameful Experience, Online Business, Case Study

\section{Introduction}

In the coronavirus epidemic today, the importance of online business is increasingly highlighted (Ahani \& Nilashi, 2020). How to engage people in online commerce has become a key issue (Tatoglu et al., 2020). Parallel to the development of online businesses, gamification is more and more widely used in business (Werbach, 2014; Robson et al., 2015), as it can arouse positive affective and serve as a force that inspires people's inner potential (Seaborn \& Fels, 2015). Specifically, in business context, gamification can be used to increase the cus- 
tomer engagement (Harwood \& Garry, 2015), brand loyalty (Yang et al., 2017) and advertisement effectiveness (Hamari \& Koivisto, 2015). According to the report from Gartner (2016), gamification was adopted by $70 \%$ of the world's largest companies in 2015 , which drove $50 \%$ of the innovation. Though gamification has been widely used, the fact is that not all endeavors have been successful. Gartner (2012) pointed out that $80 \%$ of the companies that use gamification have failed in their attempts. This is mainly due to a lack of systematic understanding and effective use of gamification (Robson et al., 2015).

As the motivation affordance, game design features are the core part of gamified business (Mekler et al., 2017). In the existing literature, there are different models to categorize gamification features such as MDM, DMC, DME, etc. (Blohm \& Leimeister, 2013; Werbach \& Hunter, 2015; Robson et al., 2015). However, the elements summarized in these models are all proposed based on the early research of gamification. With the development of the application of gamification, the core elements of gamification are expanding. In addition, none of the existing models are specific to online commerce (Fu et al., 2020; Tung et al., 2019). Therefore, gamification model of online business needs to be further improved.

Thus, this study intends to fill out the gaps mentioned above by analyzing five categories of gamification features based on the case study of Xian-Yu that represents a successful gamified online trading platform in China. The next section covers the literature review related to the concept of gamification and gamification features. In the third section, we put forward a new gamification feature model called SMART (S-Story; M-Mechanics; A-Aesthetics; R-Relation; $\mathrm{T}$-Technology) model. In the fourth section, we use the case study of Xian-Yu platform to explain how SMART model gamifies online business. The last section makes a conclusion of this study and points out the theoretical contributions and practical implications.

\section{Key Concept and Literature Review}

\subsection{Concept of Gamification}

The word gamification first appeared in Brett Terrill's blog and was described as "applying game mechanics to web portals to increase user involvement." Later, many scholars supplement and develop the concept of gamification from their own research direction (Koivisto \& Hamari, 2019; Xu et al., 2017; Deterding et al., 2011). One of the most representative and widely accepted views is the experience of using game elements in non-game context (Huotari \& Hamari, 2017).

The experiences created by game features refer e.g. to senses of enjoyment, flow, autonomy, mastery, accomplishment, etc., that are considered to be induced by games and gameplay (e.g. Ryan \& Deci, 2008). The application of gamification features to non-game contexts has been practiced in many areas (e.g., business, education, etc.) and has been shown to have a positive impact. Game 
features have the ability to engage and excite, and when playing games, people commonly experience e.g. mastery, competence, enjoyment, immersion, or flow (Huotari \& Hamari, 2017). Robson et al. (2016) points out that "Gamified" experiences can focus on business processes (e.g., customer acquisition). Therefore, marketing departments can gamify their business activities to increase consumers' engagement by rewarding success and providing motivation.

\subsection{Prior Research on Gamification Elements}

Gamification features play very important roles in the successfulness of gamification design. At present, motivation-based theories are the most important theoretical foundation for gamification design which include intrinsic and extrinsic motivational theory, user-centered design theory, work design theory and so on. These theories are trying to explain how gamification motivates users to participate (Ryan \& Deci, 2006; Locke \& Latham, 2004). Table 1 shows the gamification models from the existing literature. According to intrinsic and extrinsic motivational theories, Blohm \& Leimeister (2013) point out that gamification design is composed of Mechanics, Dynamics, and Motivation. According to user-centered design theory and work design theory, Werbach \& Hunter (2015)

Table 1. Typical framework of gamification elements.

\begin{tabular}{|c|c|c|c|}
\hline \multicolumn{2}{|c|}{ The framework of gamification } & Specific element & \multirow{3}{*}{$\begin{array}{l}\text { Relevant literature } \\
\text { Blohm and Leimeister } \\
\text { (2013) }\end{array}$} \\
\hline \multirow{2}{*}{ MDM Model } & Mechanics & $\begin{array}{l}\text { Behavioral identification documents, integrating system, badge, cup, ranking, } \\
\text { grade, reputation score, team mission, time pressure, task mode, passing level } \\
\text { mode, pictorial signal, virtual trade }\end{array}$ & \\
\hline & Dynamics & Explore, collect, compete, gain position, cooperate, and challenges & \\
\hline \multirow{3}{*}{ DMC Model } & Dynamics & Constraint, emotion, narration, development, relation & \multirow{3}{*}{$\begin{array}{l}\text { Werbach and Hunter } \\
\qquad(2015)\end{array}$} \\
\hline & Mechanics & $\begin{array}{l}\text { Challenge, chance, competition, cooperation, feedback, access to resources, } \\
\text { reward, trade, round, winning state }\end{array}$ & \\
\hline & Components & $\begin{array}{l}\text { Achievement, avatars, badge, hit a ghost, collect, fight, content deblocking, grant, } \\
\text { ranking list, grade, count, task, social atlas, team, virtual product }\end{array}$ & \\
\hline \multirow{3}{*}{ MDE Framework } & Mechanics & Organization mechanics, rule mechanics, process mechanics & \multirow{3}{*}{ Robson et al. (2015) } \\
\hline & Dynamics & $\begin{array}{l}\text { The change in players' behaviors (cooperation, competition, observation, } \\
\text { participation, dropping out, and cheating) }\end{array}$ & \\
\hline & Emotions & Positive emotion, passive emotion & \\
\hline \multirow{4}{*}{ SMAT Model } & Storytelling & Focused thread, spiritual visualization, empathy, task situation, a guide to action & \multirow{4}{*}{ Hofacker et al. (2016) } \\
\hline & Mechanics & Ranking lists, credits, progress charts, badges & \\
\hline & Aesthetics & Visual signals, appearance & \\
\hline & Technology & Medium, like broadband network, wireless network & \\
\hline \multicolumn{2}{|c|}{ Direct Visualization Elements } & Scores, badges, ranking lists, progress charts, plots, visual signals, team members & Sailer et al. (2017) \\
\hline \multicolumn{2}{|c|}{$\begin{array}{l}\text { Virtual Community Gamification } \\
\text { Elements }\end{array}$} & $\begin{array}{l}\text { Game credits, social credits, exchangeable credits, grades, ranking lists, } \\
\text { exchanges, plots, virtual identities, collections }\end{array}$ & Scheiner et al. (2017) \\
\hline
\end{tabular}

Sources: Literature reviews. 
proposed the DMC (Dynamics, Mechanics, and Components) models of gamification elements. These three elements constitute the hierarchical structure for the design of gamification. The MDE model is also established according to the theory of work design (Robson et al., 2015). It considers the relationship among players, designers, observers and spectators (Robson et al., 2016). Based on business's ecosystem, Hofacker et al. (2016) constructed a quadrivalent-element SAMT model that includes the Story, Aesthetics, Mechanics, and Technology.

In addition to the above models, based on self-determination theory and goal setting theory (Ryan \& Deci, 2006; Locke \& Latham, 2004), elements such as points, badges, rewards, rankings, levels and reputation are emphasized and applied in gamification design in order to awaken people's competent, autonomous, and relational motivation (Scheiner et al., 2017). Therefore, these elements can be considered as important visualization and virtual community elements in gamification design (Sailer et al., 2017).

The existing research results provide very valuable references for the subsequent construction of gamification elements. However, there is no consensus on the classification of gamification elements. In specific research situations and perspectives, new gamification element models can be constructed.

\section{Gamification Features from the Lens of User Engagement: SMART Model}

Gamification features are a key factor that affects user participation motivation and further determines the success of the gamified system (Huotari \& Hamari, 2017; Bharamgoudar et al., 2016). Therefore, it is suitable to construct gamification model from the perspective of user motivation. According to self-determination theory, user engagement motivation can be divided into utilitarian motivation, hedonism motivation, and social motivation (Ryan \& Deci, 2006). In this paper, we construct a new gamification feature model based on these three motivations. On the foundation of the latest and most comprehensive SMAT model (Hofacker et al., 2016) and with the combination of the MDM model (Blohm \& Leimeister, 2013), DMC model (Werbach \& Hunter, 2015) and MDE framework (Robson et al., 2015), a SMART model (see Figure 1) is proposed. It highlights every element for each feature and each feature relates to each motivation. SMART model depicts the process of applying the gamification system from five dimensions, including S-Story, M-Mechanics, A-Aesthetics, R-Relation, and $\mathrm{T}-\mathrm{Technology}$.

\subsection{Story}

The story involves five elements, which including task context, mental imagery, convergent process, empathy, and action guide. According to hedonism motivation, a proper description of background and meaning of the task can help people understand the objective of the task and thus enjoy the process of doing it more (Green \& Brock, 2000). What's more, participants can acquire mental images from the task description and then form a sense of self-perception through 


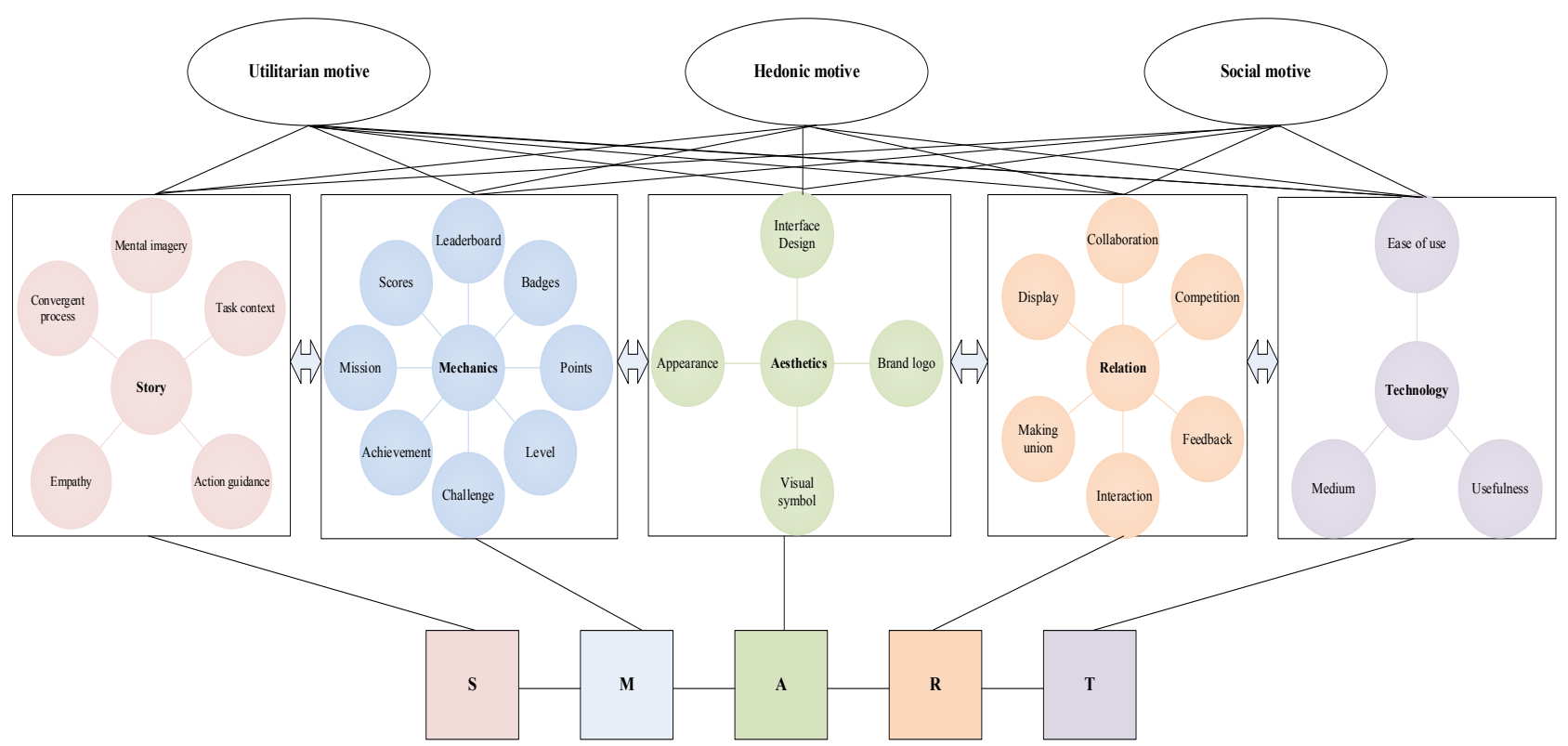

Figure 1. The framework of gamification SMART model.

empathy (Van Laer et al., 2014). Based on utilitarian motivations, designers can set up an action guide in stories, which tells users how to participate, and also provide relevant rules and processes. In addition, designers can also set up relevant rules for different types of users, such as cooperation and competition rules, based on social purpose motivation.

\subsection{Mechanics}

The mechanic is the direct factor used to stimulate users' behavior (Hofacker et al., 2016), including achievements, challenges, badges, scores, leaderboard, missions, levels, and points. Different elements have different incentive mechanisms. For example, the effect of leaderboard comes from competitive and competent motivation which are more utilitarian while the effect of avatars comes from hedonic motivation (Koivisto \& Hamari, 2019; Xu et al., 2017). Thus, designers can choose appropriate mechanics for their gamification design (Deterding et al., 2011).

\subsection{Aesthetics}

Mainly based on users' hedonism motivation, aesthetic is raised (Leclercq et al., 2017). In gamification designs, it is very important to make the aesthetic of the design in line with the user's aesthetic appreciation (Hofacker et al., 2016; Jylhä \& Hamari, 2019). For example, when the online business use gamification design, aesthetic elements of an APP or a website must be considered. Specifically, the designs need to consider if the color, visual symbol, and appearance styles of gamified elements can meet the aesthetic requirements of the target groups. When the design of a gamified element does not meet users' aesthetic requirements, it is very likely that users may not be motivated to participate in activities 
(Hamari et al., 2014). Moreover, the aesthetics designs are also likely to enhance a user's social motivation. People are more expected to make friends and organize teams with apps and communities that are more aesthetically pleasing to their target users (Looyestyn et al., 2017), this effect is more significant among women (Koivisto \& Hamari, 2014).

\subsection{Relation}

Relation puts forward mainly based on users' social motivation. In the studies of existing gamification element models, relation plays a crucial role. However, almost all models (see Table 1 ) mention relation feature, but none of them treat it as a separate feature. In fact, new-generation users are increasingly concerned with their social needs (Rodrigues et al., 2016). Therefore, more and more businesses are using web technology to develop and build their online communities to maintain online social relationships among users (Scheiner et al., 2017). As for gamification design, relation feature should be considered. Specifically, relation feature includes competition, collaboration, interaction, display, feedback and making friends or teams. If these gamified relation elements are applied, two relationships are constructed. The first relationship is between users and products, gamified relation elements can prompt users to make feedback, recommendation and repeated purchase of products and so on. The second relationship is among users themselves. That is, gamified relation elements can make users more willing to cooperate or compete with each other (Rodrigues et al., 2016).

\subsection{Technology}

Technology feature is a key part of the gamification experience (Hofacker et al., 2016). It includes perception of technology (e.g. ease of use, usefulness) and medium (e.g. AR, VR, AV, AI, etc.). First of all, by stimulating people's utilitarian motivation, technology elements can give people a direct sense of the ease of use and usefulness of gamification designs, which can make users accept gamified designs easier (Yang et al., 2017). Secondly, by stimulating users' hedonistic motivation with the technology of AR, VR, etc., users can enhance their pleasant experience of gamification and become more willing to participate in gamification projects (Scheiner et al., 2017). In addition, when technology elements make communication more convenient, they also indirectly influence users' social motivation (Mitchell et al., 2017).

\section{SMART Gamification Model Apply in Xian-Yu Platform}

\subsection{Case Selection and Data Source}

This paper will further test the effectiveness of SMART model through the case of Xian-Y $\mathbf{u}^{1}$ website applying gamification to business operation. Specifically, the case of Xian-Yu can show how the gamification design of SMART model helps ${ }^{1}$ URL of Xian-Yu: https://2.taobao.com/. 
to get more users involved and drives the success of Xian-Yu's business. The following are the reasons why use Xian-Yu as the case study. Firstly, Xian-Yu adopts many gamification designs in its operational processes. Secondly, Xian-Yu's operation has proven to be a great success, which is mainly because of its attraction to a large number of active users. Thirdly, Xian-Yu's operation includes good use of internet technology and the management of online communities, which is a typical online case study.

Information and data related to Xian-Yu were collected in the principle of evidence triangle, mainly from Xian-Yu's homepage, media reports, and semi-structured interviews with Xian-Yu users regarding their experiences. For the semi-structured interviews on the user experience, 45 participants $\left(M_{\text {age }}=22\right.$, $54 \%$ female, Major in business administration) were interviewed from April 3, 2020, to May 10, 2020. About 50\% of the interviewees had used Xian-Yu for more than three months. Therefore, the interview data are suitable for this case.

\subsection{Overview of Xian-Yu Platform}

$\mathrm{Xian}-\mathrm{Yu}$ is an online trading platform for second-hand goods under the Alibaba Corporation in China (Xian-Yu's interface see Appendix Figure A1). It currently has both desktop and mobile app versions (iOS and Android). As long as a member logs in via their Taobao or Alipay account, they can sell the "items bought" in their Xian-Yu account with one click. They can upload pictures of second-hand items through their mobile phone and conduct online transactions without going through the complex process of opening up an online shop.

Xian-Yu has witnessed rapid growth and development since its official launch in June 2014, which mainly due to the significant increase of its user participation frequency, user participation duration, and numbers of users. According to Quest Mobile (a consulting corporation), the number of DAU (daily active users) on Xian-Yu reached a record high of 10 million in 2019. In terms of the number of daily uses per person, Xian-Yu's monthly average is 6.8 times, which is more than the 5.8 of Taobao and the 5.1 of Jingdong Mall. In terms of the per capita daily use duration, it is 25.8 minutes for Xian-Yu, which is longer than other similar online shopping apps (e.g. Taobao, jd.com, Zhuanzhuan, etc.) According to the data released by Chen Wei-ye, the head of Xian-Yu, Xian-Yu now accumulated two hundred million users. Nearly $70 \%$ of Xian-Yu users were born post-1990s, and the number of items that passed through this platform reached 340 million pieces. Throughout the development of Xian-Yu project, it can be seen that the wide use of gamification is an outstanding feature of Xian-Yu. The success of Xian-Yu is reflected in all aspects of SMART model. Gamification design of Xian-Yu can be further explained through the five features of story, mechanics, aesthetics, relation, and technology.

\subsection{Xian-Yu's SMART}

Xian-Yu's Story

Before Xian-Yu's launch, Taobao first investigated users through an online 
survey. The results showed that almost everyone has second-hand items and that more than half of all users tended to put them aside without further use. The reason for this is that most users did not have the time or energy to resell the second-hand goods, while some users even did not know where they could sell their second-hand goods. In this context, Taobao launched an online trading platform Xian-Yu that catered to many users with the idea of letting idle products be used again. The story of Xian-Yu is described on its official website ${ }^{2}$. "Xian-Yu" means "idle fish" in Chinese, so its slogan of "Let your idle fish swim" has become the convergent clue of its story and mental imagery (see Appendix Figure A1). In marketing, Xian-Yu calls upon consumers "to find new owners, to share with others, to make new friends...". Therefore, Xian-Yu is both a trading platform ${ }^{3}$ and a platform where people who share a common interest can gather. Users' utilitarian motivation to sell for a profit, hedonistic motivation to share items, and social motivation to find common interests have all been motivated by Xian-Yu's story. The deep influence of Xian-Yu's story on the above three user's motivations can also be seen from the interviewees' answers to why they use Xian-Yu (Table 2).

Thus, Xian-Yu's story of "find new owners, share with others, make new friends" has become deeply rooted in the minds of consumers.

\section{Xian-Yu's Mechanics}

The mechanics of Xian-Yu has the most direct effect on its users' participation rate. Firstly, after logging into the Xian-Yu interface, users can gain a sea shell and check their credit scores (see Appendix Figure A2). Seashells are equal to points, which can be used as a registration fee to participate in some activities held in Xian-Yu. More successful transactions lead to a higher credit score. Secondly, if the user has some products for sale, he can click on the "shine" button every day (see Appendix Figure A3). This can update the product for sale and increase the visibility of the product, making the product more likely to be sold. Thirdly, Xian-Yu launches “Xian-Yu Top Sales" activity. According to the user's trading situation, a sales rank is assigned to the users, manifested in a Bronze Star, Silver Star, or Gold Star. But these stars have time limits. Take the first

Table 2. Interviewees' answers to why they use Xian-Yu.

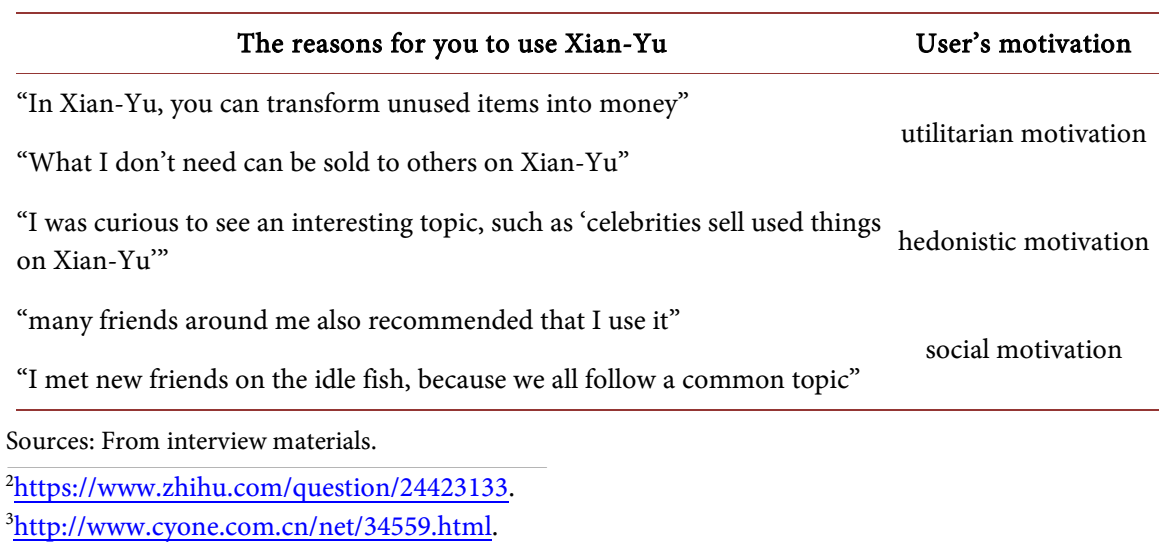


Xian-Yu Top Sales Activity as an example. After the competition, the person who won the medal will keep the title for 3 months. After 3 months, a new assessment will be conducted. During Xian-Yu Top Sale Activity, higher sales lead to higher grades. Moreover, Xian-Yu officially announced that Xian-Yu's top seller can receive cash bonus. In addition, Xian-Yu has launched "Yu-Tang" (fishpond: a kind of user community, in Xian-Yu, it is named $\mathrm{Yu}$-Tang) in its latest version (see Appendix Figure A4). Yu-Tang refers to small community established by users with a common interest. After joining such a small group, users can receive all kinds of information about second-hand transactions in this community in a timely manner. There are different levels of Yu-Tang, with five main indicators for leveling them up, which include the number of members, the number of users releasing second-hand product information, the number of interactive users, the number of users closing a deal, and weekly customer retention rate. As mentioned above, Xian-Yu gives full consideration to users' utilitarian, hedonic, and social motivations. Through the integrated designs of gamification mechanics, such as grades, credits, medals, achievements, and rankings, Xian-Yu has effectively motivated users' motivation and further their participation.

During the interviews, each interviewee mentioned gamified mechanics of $\mathrm{Xian}-\mathrm{Yu}$ to different degrees and that they agreed that such gamified mechanics are an effective means of driving them to engage with Xian-Yu. Table 3 summarizes the interviewees' responses to questions related to these gamification mechanics, such as "What do you think is special about Xian-Yu", "What content do you like about Xian-Yu", "What elements do you noticed in Xian-Yu", and so on.

Table 3. Gamified mechanics mentioned by the interviewees and their evaluations.

\begin{tabular}{|c|c|c|c|c|c|}
\hline \multirow{2}{*}{ Mechanics } & \multirow{2}{*}{$\begin{array}{l}\text { Mentions } \\
\text { frequency }\end{array}$} & \multirow{2}{*}{ Percentage } & \multicolumn{3}{|c|}{ Evaluation } \\
\hline & & & Positive & Negative & Neutral \\
\hline Treasure polishing (sign-in) & $13 / 45$ & $28.9 \%$ & 11 & 1 & 1 \\
\hline Xian-Yu coin (credits) & $29 / 45$ & $64.4 \%$ & 21 & 1 & 7 \\
\hline Xian-Yu Talent (medal and achievement) & $6 / 45$ & $13.3 \%$ & 4 & 0 & 2 \\
\hline $\begin{array}{l}\text { Yu-Tang (level, ranking list-question-answering rank, sign-in rank, } \\
\text { environmental protection rank, and community) }\end{array}$ & $42 / 45$ & $93.3 \%$ & 38 & 2 & 2 \\
\hline Xian-Yu Webcast (bullet screen) & $24 / 45$ & $53.3 \%$ & 11 & 9 & 4 \\
\hline Xian-Yu Family (Create a topic and vote) & $20 / 45$ & $44.4 \%$ & 18 & 0 & 2 \\
\hline Likes for Items on Sale (like or be liked) & $15 / 45$ & $33.3 \%$ & 12 & 1 & 2 \\
\hline $\begin{array}{l}\text { Xian-Yu Selection (titles like talent purchase, worth buying, and sold out } \\
\text { in the blink of an eye) }\end{array}$ & $3 / 45$ & $6.7 \%$ & 3 & 0 & 0 \\
\hline Xian-Yu Talk (prizes and lucky draw) & $7 / 45$ & $15.6 \%$ & 4 & 0 & 3 \\
\hline Xian-Yu Research Institute (ranking for hot-selling products) & $2 / 45$ & $4.4 \%$ & 2 & 0 & 0 \\
\hline Xian-Yu Happy Auction (for completion, fun, or collection) & $3 / 45$ & $6.7 \%$ & 3 & 0 & 0 \\
\hline
\end{tabular}

Sources: From interview materials. 
As shown in Table 3, Yu-Tang is the most popular function of Xian-Yu, as 93\% of the respondents mentioned it and gave it positive reviews. 38 respondents expressed their preference for the community interaction functionality of $\mathrm{Yu}$-Tang, including feedback, topic discussions, and online and offline activities. Furthermore, the account level and rankings can prompt them to continue to participate in $\mathrm{Yu}$-Tang. Some respondents said that in Xian-Yu, they are able "to make friends", "to clear up the doubts in their hearts", "to buy good things," and "to add novelty feelings". Only two interviewees mentioned that they don't like ranking because it made them feel pressure. In addition to $\mathrm{Yu}$-Tang, the interviewees frequently mentioned a number of other topics, including Xian-Yu Coin, Xian-Yu Family, Xian-Yu live webcast, thumb ups for items, and "shine" the items on sale. For example, "Every time after I log in, I would check if my credit score, sign-in, and thumbs-up have increased", "Increases in thumbs-up and credits make me feel good. If not, I would be a little lost", "More sign-ins and Xian-Yu coins can boost the exposure of items, which makes it easier to sell", "Xian-Yu coins and thumbs-up are very useful". A total of 50\% of the respondents mentioned Xian-Yu live webcast, but not all people like the webcast because they have different feelings about the bullet screen. Some respondents watch Xian-Yu live webcast or login to the Xian-Yu website simply because they are keen on bullet screens. However, other respondents have negative views towards the bullet screen and they have even refused to watch the Xian-Yu live webcasts due to the bullet screen. This shows that not all of the gamification mechanics play a positive role in motivating the users. Therefore, the design must fully consider users' demand.

\section{Xian-Yu's Aesthetics}

Xian-Yu's interface uses a bright yellow color as the base color with a lovely fat fish as its brand logo which makes users have the perception that it is lovely, simple, lively, and cost-effective. Meanwhile, the various gamification features are also clearly displayed. Xian-Yu aesthetics perception can be seen through the pictures that are shown in Appendix Figures A1-A5.

In the interviews, interface design, logo, emblem, information prompt design, and the image of the Xian-Yu Family were mentioned several times. Most interviewees like the "aesthetics" of Xian-Yu. "Lovely yellow fish", "lively and funny", "direct and clear", "simple and bright", "lighthearted feeling", and "strong visual appeal" were the words frequently used by the interviewees to describe Xian-Yu's aesthetics. In particular, the cartoons on Xian-Yu Family received unanimous praise from the interviewees. Many respondents hold the views that the comic characters, stickers, and wallpapers in the Xian-Yu Family are "fun", "cute" and "very stylish". A total of $30 \%$ of the respondents said they had become fans of Xian-Yu just because they initially fell for the comic characters in the Xian-Yu Family. As a result, it can be seen that the aesthetic design of Xian-Yu conforms to the aesthetic standards of its user group, which stimulates the hedonic motivation of users and further stimulates their participation. 


\section{Xian-Yu's Relation}

"Relation" is one of the most prominent features in Xian-Yu's gamification. "Yu-Tang", "Xian-Yu live webcast" and "Xian-Yu Family" are three important projects that can illustrate Xian-Yu's relation (see Appendix Figure A5).

As an online community of Xian-Yu, Yu-Tang has attracted and gathered a large number of post-1990s participants. Apart from making money by selling unused goods, Yu-Tang help the post-1990s generation creating their own unique lifestyle and culture. Yu-Tang's operation mode is similar to the BBS (Bulletin Board System), and the role of the Yu-Tang owner corresponds with that of the administrator of the BBS. By March 2017, according to the official data provided by Xian-Yu, the number of Yu-Tang communities had reached 410,000. Yu-Tang communities have all sorts of fun names, such as "The Temptation of Lipstick", "Han-style Clothing", "Cosplay Together", "Ancient Handmade Articles", "Motorcycles", "Being A Lens Fan is not a Waste of Money" and so on. Through various gamification mechanics, such as follow, thumbs-up, make comments, more and more users participate Yu-Tang. About $27 \%$ of the interviewees said they has joined at least one Yu-Tang. Almost all interviewees gave positive comments to Yu-Tang (see Table 4).

As for why they joined $\mathrm{Yu}$-Tang, the interviewees gave answers like "They can find more people with the same hobbies", "Knowing people outside their social circles is more important and interesting than transactions" and so on. Moreover, the interviewees cared greatly about the Yu-Tang topics and the feedback they received from the members. Some who operated Yu-Tangs were concerned with the grades for their Yu-Tangs' levels and hoped to obtain Yu-Tangs with higher level through their own efforts. It can be seen that the gamified design of Yu-Tangs can improve the relationships among Xian-Yu users and fully satisfy users' social motivations and hedonic motivation.

Xian-Yu Family succeeds in combining second-hand businesses and cartoons. At present, the blog has more than 300,000 followers. Xian-Yu family members include Cousin, Qiqi, Gai sir, and others. At the same time, the Xian-Yu family will periodically host some topical activities such as "Say something that is a sentence long to respond to people who say that you are fat" or "How hot are you?". Users can vote on how interested they are in the topic so as to achieve an

Table 4. Interviewees' comments on Yu-Tang.

$\begin{array}{cc}\text { Comments } & \text { Percentage } \\ \text { The topic is interesting. } & 77 \% \\ \text { I will introduce it to other people. } & 56 \% \\ \text { I visit it every day. } & 28 \% \\ \text { I like asking questions or responding to others in Yu-Tang. } & 32 \% \\ \text { I will try to join at least one Yu-Tang. } & 30 \% \\ \text { I make some friends through Yu-Tang. } & 26 \%\end{array}$

Sources: From interview materials. 
interactive effect. Many interviewees highly appraised Xian-Yu family and say that they are surprising, interesting, and full of expectations. Xian-Yu family also satisfies users' social and hedonic motivations.

Xian-Yu live broadcast went online in November 2016. It provides Xian-Yu auction that can auction off products through live online broadcasts. Buyers can watch and participate in the auction. By clicking on the items in the live broadcast interface, users can go to the page for the auctioned goods. As a popular tool in the present online community, live broadcasts have also used many gamified designs. For example, audiences can interact with those who hosting the live broadcast by sending gifts to them and proposing their own ideas on the bullet screen. The whole interacted process strengthens the relationships among users, corporations, and products while fulfilling users social and hedonics motivations.

\section{Xian-Yu's Technology}

On the one hand, Xian-Yu' technology ensures users' knowledge of its ease of use and usefulness. Users can sell things in Xian-Yu without registering a store. The latest Xian-Yu has a "one click resells" function. With this function, users can sell the products that they brought in Taobao very easy. More than $90 \%$ of the interviewees thought that Xian-Yu's "one click resells" function is easier to operate than they imagined. It satisfies users utilitarian motivations and make them has more willing to use it. On the other hand, Xian-Yu's use of medium remains unexplored. So far, it doesn't use any technology of AR, VR, AV, AI, etc. Therefore, the driving ability of Xian-Yu technology in improving users' hedonic motivation still needs to be enhanced.

According to the above discussion, Xian-Yu has employed gamification design which includes story, mechanics, aesthetics, relations, and technology. These five features make up the SMART model of gamification. They meet users' utilitarian, hedonistic, and social motivation, thus encourage users to constantly participate in Xian-Yu transactions and finally enabling Xian-Yu to achieve successfulness.

\section{Conclusion and Discussion}

Gamification is a new tool in the field of business management. Firstly, this paper defined and deconstructed gamification. Then, it constructed SMART model of gamification from the lens of user engagement in online business for the first time. Thirdly, the successful operation of Xian-Yu was used as an example to illustrate the application of SMART model and its effects. Specifically, Gamification's story design cannot be tedious, the key is that the spiritual clues need to be simple and clear to deliver to users. For mechanics design in online gamification, multiple game elements can be used simultaneously, such as points, leaderboard, badges, etc. More importantly, if these mechanic elements can cause interaction between consumers, it will make the effect of gamification last longer. For aesthetic design of online business gamification, aesthetic design needs to conform to the aesthetic standards of the target users. For relationship design, in addition to motive online user interaction, it is also necessary to consider how to motive 
online and offline interaction. Last but not least, for technology design, in addition to the design of the usefulness and ease of use of the technology itself, it should also consider the application of the mediums (AR, VR, AI, etc.).

\subsection{Theoretical Implication}

The main contribution and innovation of this research can be presented in theoretical implication. That is, by summarizing the previous gamification models, this paper systematically summarizes the components of gamification, and proposes a more comprehensive gamification component model from the perspective of user participation motivation-SMART model. SMART model consists of story, mechanics, aesthetics, relation, and technology. Each feature has its specific element composition, and the incentive function of these elements is inseparable from user's three kinds of motivations, including utilitarian, hedonic, and social motivations. Thus, the effect of gamification elements and their mechanism are clearly presented.

\subsection{Management Implication}

The main contribution and innovation of this research can be also presented in management implication. Based on the case of Xian-Yu's gamification, this research combines the newly proposed theoretical model (SMART model) with practice. It not only tests the validity of the SMART model, but also provides a reference scheme for designing gamification in actual online enterprises. Specifically, SMART model can be used in practice to help online corporations improve their relationships with users, strengthen users' loyalty, enhance user participation, and further promote corporate development. First, companies should fully consider the design of the five features in SMART model when carrying out gamification application. And the design of story, mechanics, aesthetic, relation and technology should be considered as a whole. Second, SMART model is proposed base on users' motivations. Thus, a corporation can only effectively implement SMART model after understanding its target users' real needs. Thirdly, SMART model is dynamic. With the advancement of technology, the weight of the elements in SMART model may change, and the enterprise should pay attention to these changes in gamification design.

\subsection{Limitation and Future Study}

Through a case analysis, this paper explores the effective influence of gamification on online business, which has some limitations in the research methods. In the future, the quantitative analysis method should be adopted and empirical studies (e.g. experiment, questionnaire, survey) can be used to examine the effect of gamified elements on users' psychology and behavior. The research conclusion will have greater theoretical and practical contributions.

\section{Acknowledgements}

This work is supported by the National Natural Science Foundation of China 
(NSFC) [Project No. 71702100]. The author would like to thank Professor Shengce Ren from Tongji University who participated in the discussion of SMART model and give great suggestions.

\section{Conflicts of Interest}

The author declares no conflicts of interest regarding the publication of this paper.

\section{References}

Ahani, A., \& Nilashi, M. (2020). Coronavirus Outbreak and Its Impacts on Global Economy: The Role of Social Network Sites. Journal of Soft Computing and Decision Support Systems, 7, 19-22.

Bharamgoudar, R., Elmqvist, K., Qiu, S., et al. (2016). Tailoring and Utilising Gamification to Facilitate Behaviour Change. http://hdl.handle.net/10044/1/33287

Blohm, I., \& Leimeister, J. M. (2013). Gamification Design of It-Based Enhancing Services for Motivational Support and Behavioral Change. Business \& Information Systems Engineering, 5, 275-278. https://doi.org/10.1007/s12599-013-0273-5

Deterding, S., Dixon, D., Khaled, R., \& Nacke, L (2011). From Game Design Elements to Gamefulness: Defining Gamification. In Proceedings of the 15th International Academic MindTrek Conference: Envisioning Future Media Environments (pp. 9-15). ACM. https://doi.org/10.1145/2181037.2181040

Fu, H., Manogaran, G., Wu, K., Cao, M., Jiang, S., \& Yang, A. (2020). Intelligent Decision-Making of Online Shopping Behavior Based on Internet of Things. International Journal of Information Management, 50, 515-525.

https://doi.org/10.1016/j.ijinfomgt.2019.03.010

Gartner Top 10 Strategic Technology Trends for 2012 (2012).

https://www.gartner.com/smarterwithgartner/gartner-top-10-strategic-technology-tren ds-for-2012/

Gartner Top 10 Strategic Technology Trends for 2016 (2016). https://www.gartner.com/smarterwithgartner/gartner-top-10-strategic-technology-tren ds-for-2016/

Green, M. C., \& Brock, T. C. (2000). The Role of Transportation in the Persuasiveness of Public Narratives. Journal of Personality and Social Psychology, 79, 701-721. https://doi.org/10.1037/0022-3514.79.5.701

Hamari, J., \& Koivisto, J. (2015). Why Do People Use Gamification Services? International Journal of Information Management, 35, 419-431. https://doi.org/10.1016/j.ijinfomgt.2015.04.006

Hamari, J., Koivisto, J., \& Sarsa, H. (2014). Does Gamification Work?-A Literature Review of Empirical Studies on Gamification. 2014 47th Hawaii International Conference on System Sciences, Waikoloa, HI, 6-9 January 2014, 3025-3034.

https://doi.org/10.1109/HICSS.2014.377

Harwood, T., \& Garry, T. (2015). An Investigation into Gamification as a Customer Engagement Experience Environment. Journal of Services Marketing, 29, 533-546. https://doi.org/10.1108/JSM-01-2015-0045

Hofacker, C. F., De Ruyter, K., Lurie, N. H., Manchanda, P., \& Donaldson, J. (2016). Gamification and Mobile Marketing Effectiveness. Journal of Interactive Marketing, 34, 25-36. https://doi.org/10.1016/j.intmar.2016.03.001 
Huotari, K., \& Hamari, J. (2017). A Definition for Gamification: Anchoring Gamification in the Service Marketing Literature. Electronic Markets, 27, 21-31. https://doi.org/10.1007/s12525-015-0212-Z

Jylhä, H., \& Hamari, J. (2019). An Icon That Everyone Wants to Click: How Perceived Aesthetic Qualities Predict App Icon Successfulness. International Journal of Human-Computer Studies, 130, 73-85. https://doi.org/10.1016/j.ijhcs.2019.04.004

Koivisto, J., \& Hamari, J. (2014). Demographic Differences in Perceived Benefits from Gamification. Computers in Human Behavior, 35, 179-188. https://doi.org/10.1016/j.chb.2014.03.007

Koivisto, J., \& Hamari, J. (2019). The Rise of Motivational Information Systems: A Review of Gamification Research. International Journal of Information Management, 45, 191-210. https://doi.org/10.1016/j.ijinfomgt.2018.10.013

Leclercq, T., Poncin, I., \& Hammedi, W. (2017). The Engagement Process during Value Co-Creation: Gamification in New Product-Development Platforms. International Journal of Electronic Commerce, 21, 454-488. https://doi.org/10.1080/10864415.2016.1355638

Locke, E. A., \& Latham, G. P. (2004). What Should We Do about Motivation Theory? Six Recommendations for the Twenty-First Century. Academy of Management Review, 29, 388-403. https://doi.org/10.5465/amr.2004.13670974

Looyestyn, J., Kernot, J., Boshoff, K., Ryan, J., Edney, S., \& Maher, C. (2017). Does Gamification Increase Engagement with Online Programs? A Systematic Review. PLoS One, 12, e0173403. https://doi.org/10.1371/journal.pone.0173403

Mekler, E. D., Brühlmann, F., Tuch, A. N., \& Opwis, K. (2017). Towards Understanding the Effects of Individual Gamification Elements on Intrinsic Motivation and Performance. Computers in Human Behavior, 71, 525-534.

https://doi.org/10.1016/j.chb.2015.08.048

Mitchell, R., Schuster, L., \& Drennan, J. (2017). Understanding How Gamification Influences Behaviour in Social Marketing. Australasian Marketing Journal (AMJ), 25, 12-19. https://doi.org/10.1016/j.ausmj.2016.12.001

Robson, K., Plangger, K., Kietzmann, J. H., et al. (2015). Is It All a Game? Understanding the Principles of Gamification. Business Horizons, 58, 411-420.

https://doi.org/10.1016/j.bushor.2015.03.006

Robson, K., Plangger, K., Kietzmann, J. H., Mccarthy, I., \& Pitt, L. (2016). Game on: Engaging Customers and Employees through Gamification. Business Horizons, 59, 29-36. https://doi.org/10.1016/j.bushor.2015.08.002

Rodrigues, L. F., Oliveira, A., \& Costa, C. J. (2016). Does Ease-of-Use Contributes to the Perception of Enjoyment? A Case of Gamification in e-Banking. Computers in Human Behavior, 61, 114-126. https://doi.org/10.1016/j.chb.2016.03.015

Ryan, R. M., \& Deci, E. L. (2006). Self-Regulation and the Problem of Human Autonomy: Does Psychology Need Choice, Self-Determination, and Will? Journal of Personality, 74, 1557-1586. https://doi.org/10.1111/j.1467-6494.2006.00420.x

Ryan, R. M., \& Deci, E. L. (2008). A Self-Determination Theory Approach to Psychotherapy: The Motivational Basis for Effective Change. Canadian Psychology/Psychologie Canadienne, 49, 186-193. https://doi.org/10.1037/a0012753

Sailer, M., Hense, J. U., Mayr, S. K., \& Mandl, H. (2017). How Gamification Motivates: An Experimental Study of the Effects of Specific Game Design Elements on Psychological Need Satisfaction. Computers in Human Behavior, 69, 371-380.

https://doi.org/10.1016/j.chb.2016.12.033 
Scheiner, C., Haas, P., Bretschneider, U., Blohm, I., \& Leimeister, J. M. (2017). Obstacles and Challenges in the Use of Gamification for Virtual Idea Communities. In Gamification (pp. 65-76). Cham: Springer. https://doi.org/10.1007/978-3-319-45557-0_5

Seaborn, K., \& Fels, D. I. (2015). Gamification in Theory and Action: A Survey. International Journal of Human-Computer Studies, 74, 14-31. https://doi.org/10.1016/j.ijhcs.2014.09.006

Tatoglu, E., Frynas, J. G., Bayraktar, E., Demirbag, M., Sahadev, S., Doh, J., \& Koh, S. L. (2020). Why Do Emerging Market Firms Engage in Voluntary Environmental Management Practices? A Strategic Choice Perspective. British Journal of Management, 31, 80-100. https://doi.org/10.1111/1467-8551.12351

Tung, T. Y. T., Burns, L. D., \& Koenig, H. F. (2019). Choice Overload and Online Approach Behavior. International Journal of E-Business Research (IJEBR), 15, 56-72. https://doi.org/10.4018/IJEBR.2019100104

Van Laer, T., De Ruyter, K., Visconti, L. M., \& Wetzels, M. (2014). Extended Transportation-Imagery Model: A Meta-Analysis of the Antecedents and Consequences of Consumers' Narrative Transportation. Journal of Consumer Research, 40, 797-817. https://doi.org/10.1086/673383

Werbach, K. (2014). (Re)Defining Gamification: A Process Approach. In International Conference on Persuasive Technology (pp. 266-272). Cham: Springer. https://doi.org/10.1007/978-3-319-07127-5_23

Werbach, K., \& Hunter, D. (2015). The Gamification Toolkit: Dynamics, Mechanics, and Components for the Win. Philadelphia: Wharton School Press.

$\mathrm{Xu}$, F., Buhalis, D., \& Weber, J. (2017). Serious Games and the Gamification of Tourism. Tourism Manage, 60, 244-256. https://doi.org/10.1016/j.tourman.2016.11.020

Yang, Y., Asaad, Y., \& Dwivedi, Y. (2017). Examining the Impact of Gamification on Intention of Engagement and Brand Attitude in the Marketing Context. Computers in Human Behavior, 73, 459-469. https://doi.org/10.1016/j.chb.2017.03.066 
Appendix: The Screenshots of Gamification Features in Xian-Yu Platform (Chinese and English Version)
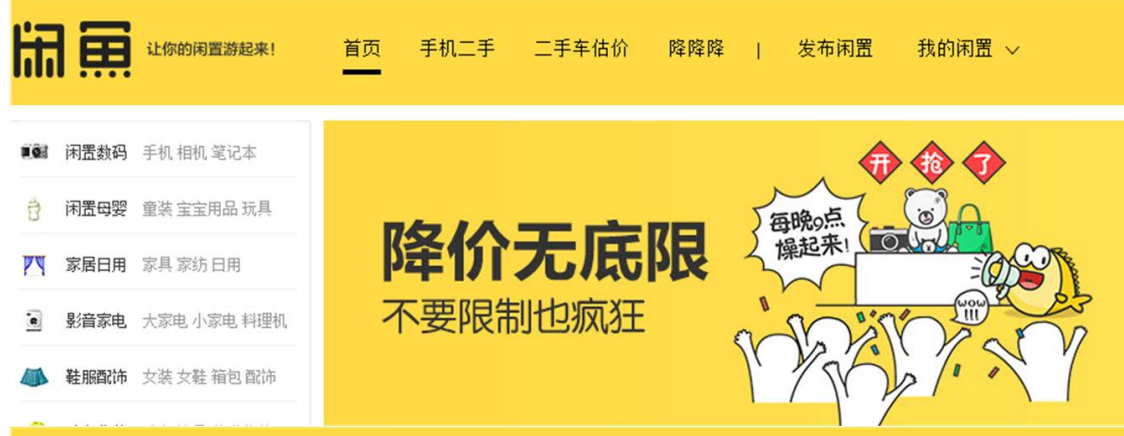

Xian Yu Let your sccondhand
product being uese again:

Home Used phone Used car valuation SALE!। Publish idle My idle
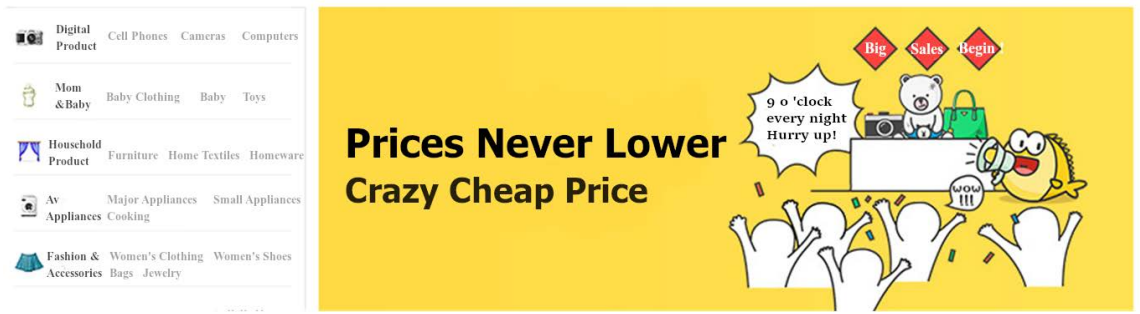

Figure A1. Interface of Xian-Yu in its homepage.

\section{kristy190}

在闲鱼赚了 40.00 元去炫耀

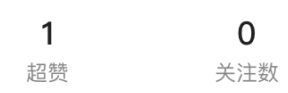

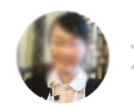

\section{kristy190}

I earned 40 Yuan in Xian Yu Show off

3
粉丝数

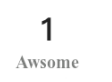

0
Following

(8) My Publish

$1>$ My Selling

$2>$ My orders

$10>\widehat{W}$ My favorites

\& Myauction

2164

My fish shell

3 Followers 


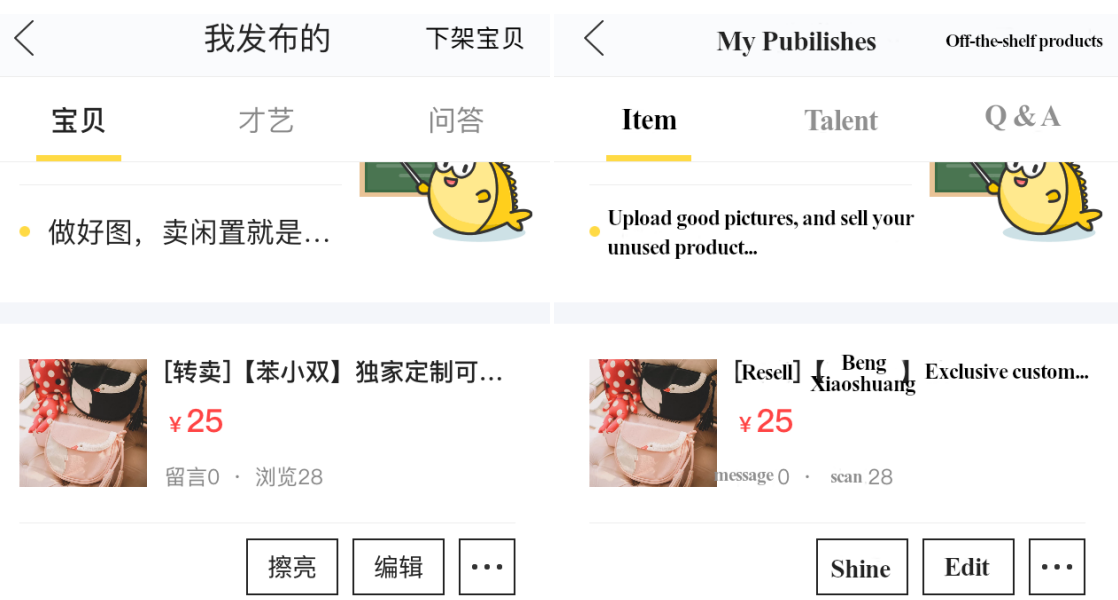

Figure A3. Xian-Yu mechanics: "Shine" the goods.

\section{鱼塘}

真实、专业的共享社区

我的鱼塘

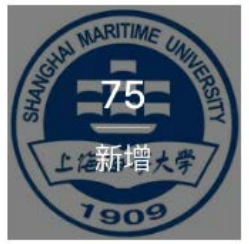

上海海事大学

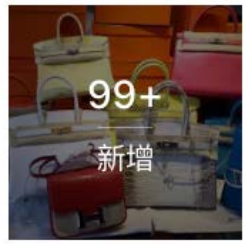

奢侈品

$Q \equiv$

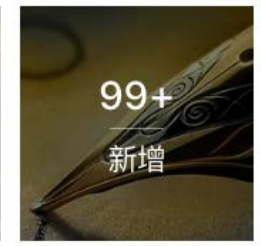

钢笔社
Yu Tang Community

Real、professional sharing community

\section{My Yu Tang Community}

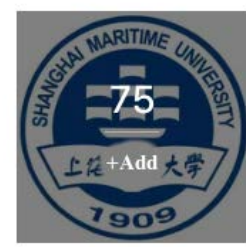

Shanghai Maritime

University

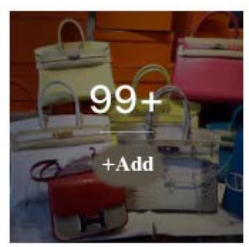

Luxury

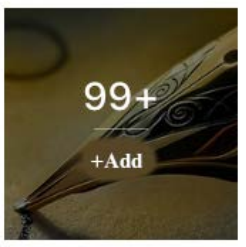

Calligraphy

Community

Figure A4. Yu-Tang: Xian-Yu's user communities. 


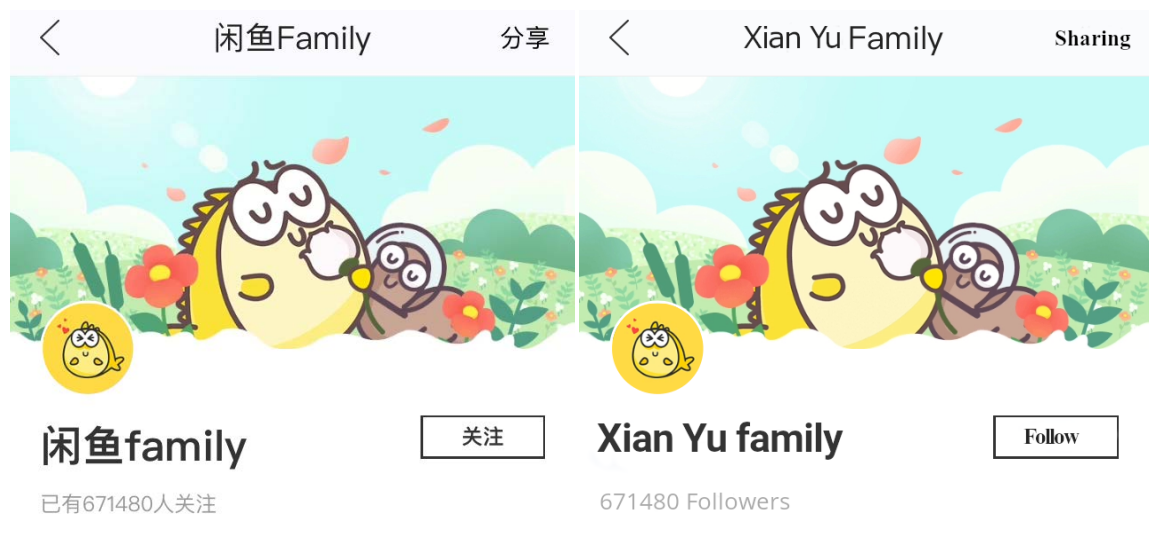

$\mathrm{Hi}$, 我们是闲鱼Family! 想知道我们发 生的有趣故事嘛? 快快关注! 我们会慢 慢讲给你听!

Hi, we are Xian Family! Want to know the funny stories that happened to us? Follow us quickly, we will tell you step by step.

$\begin{array}{ccc}< & \text { 闲鱼Family } & \text { Xian YuFamily sharing } \\ \text { | 家族介绍 } & < & \text { | Family Introduction }\end{array}$
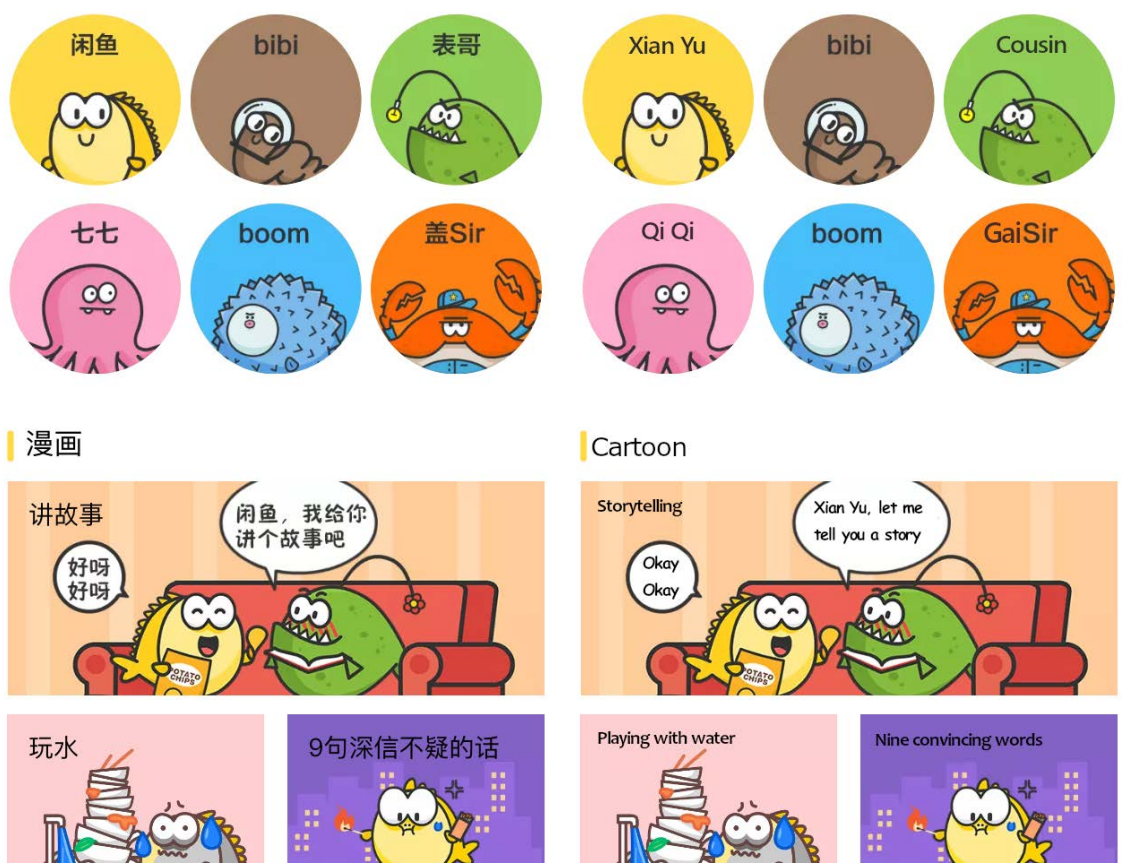

Figure A5. Xian-Yu family and comedy. 